ECS Transactions, 58 (10) 289-297 (2013)

10.1149/05810.0289ecst @The Electrochemical Society

\title{
Plasma-Enhanced Atomic Layer Deposition of III-Nitride Thin Films
}

\author{
C. Ozgit-Akgun, I. Donmez, and N. Biyikli \\ UNAM - Institute of Materials Science and Nanotechnology, Bilkent University, \\ Bilkent, Ankara 06800, Turkey
}

\begin{abstract}
AlN and GaN thin films were deposited by plasma-enhanced atomic layer deposition using trimethylmetal precursors. The films were found to have high oxygen incorporation, which was attributed to oxygen contamination related to the plasma system. The choice of nitrogen containing plasma gas $\left(\mathrm{N}_{2}, \mathrm{~N}_{2} / \mathrm{H}_{2}\right.$ or $\left.\mathrm{NH}_{3}\right)$ determined the severity of oxygen incorporation into deposited films. Lowest oxygen concentrations were attained for AIN and GaN thin films using $\mathrm{NH}_{3}$ and $\mathrm{N}_{2}$ plasma, respectively. Initial experiments have shown that GaN thin films with low impurity concentrations can be deposited when plasma-related oxygen contamination is avoided by the use of an alternative plasma source.
\end{abstract}

\section{Introduction}

III-nitride compound semiconductors and their alloys have emerged as promising materials for a wide range of electronic and optoelectronic device applications. Besides possessing very unique material properties individually, members of the III-nitride family with wurtzite crystal structure also exhibit direct band gaps, which cover a wide range with values of $6.2,3.4$, and $0.64 \mathrm{eV}$ for $\mathrm{AlN}, \mathrm{GaN}$, and $\mathrm{InN}$, respectively $(1,2)$. In this respect, ternary $\left(\mathrm{Al}_{\mathrm{x}} \mathrm{Ga}_{1-\mathrm{x}} \mathrm{N}, \mathrm{Al}_{\mathrm{x}} \mathrm{In}_{1-\mathrm{x}} \mathrm{N}, \mathrm{In}_{\mathrm{x}} \mathrm{Ga}_{1-\mathrm{x}} \mathrm{N}\right)$ and quaternary alloys $\left(\mathrm{Al}_{\mathrm{x}} \mathrm{Ga}_{\mathrm{y}} \operatorname{In}_{1-\mathrm{x}-\mathrm{y}} \mathrm{N}\right)$ of this family are particularly important since their bandgaps can easily be tuned by adjusting the alloy composition.

Although high quality III-nitride thin films can be grown at high temperatures (> $1000{ }^{\circ} \mathrm{C}$ ) with significant rates, deposition of these films on temperature-sensitive device layers and substrates (e.g., CMOS wafers, flexible polymeric substrates, etc.) necessitates the adaptation of low-temperature methods such as atomic layer deposition (ALD). ALD is a special type of chemical vapor deposition, in which the substrate surface is exposed to sequential pulses of two or more precursors separated by purging periods. When compared to other low-temperature thin film deposition techniques, ALD stands out with its self-limiting growth mechanism, which enables the deposition of highly uniform and conformal thin films with sub-nanometer thickness control. Moreover, ternary or quaternary alloys can be easily deposited by ALD, where film composition is digitally controlled by the relative number of sub-cycles.

ALD of AlN thin films has been studied by several research groups (3-9). Lee et al. (3) reported plasma-enhanced ALD (PEALD) of AlN at $350{ }^{\circ} \mathrm{C}$ using aluminum chloride $\left(\mathrm{AlCl}_{3}\right)$ and $\mathrm{NH}_{3} / \mathrm{H}_{2}$ plasma. Resulting AlN films were composed of microcrystallites of wurtzite (100) in an amorphous AlN matrix (4). Thermal $(5,6)$, plasma-enhanced (6), and 
UV-assisted (7) ALD of AlN using trimethylaluminum $\left(\mathrm{AlMe}_{3}\right)$ and $\mathrm{NH}_{3}$ have been studied within the temperature ranges of $320-470,250-470$, and $240-370{ }^{\circ} \mathrm{C}$, respectively - however, no self-limiting growth behavior was observed. This was explained by Riihela et al. (5) by the fact that surface reactions between $\mathrm{AlMe}_{3}$ and $\mathrm{NH}_{3}$ occur with reasonable rates only at temperatures where $\mathrm{AlMe}_{3}$ self-decomposition takes place. Bosund et al. (8) used the same precursors to produce AIN films by PEALD at temperatures ranging from 100 to $300{ }^{\circ} \mathrm{C}$. Films deposited in their study were amorphous except for the one grown at $300{ }^{\circ} \mathrm{C}$. Kim et al. (9), on the other hand, have reported remote plasma ALD of amorphous AlN thin films using $\mathrm{AlMe}_{3}$ and $\mathrm{N}_{2} / \mathrm{H}_{2}$ plasma.

These results show that thermal ALD of AlN using $\mathrm{AlMe}_{3}$ and $\mathrm{NH}_{3}$ is not possible since these two precursors react at temperatures where $\mathrm{AlMe}_{3}$ self-decomposition takes place (5). Therefore we lowered the deposition temperatures by activating $\mathrm{NH}_{3}$ or $\mathrm{N}_{2} / \mathrm{H}_{2}$ through remote plasma and deposited polycrystalline wurtzite AlN thin films at temperatures ranging from $100-500{ }^{\circ} \mathrm{C}(10-12)$. Deposition parameters were optimized for these processes to achieve true ALD conditions. ALD temperature windows were observed between 100-200 ${ }^{\circ} \mathrm{C}$ for both processes. Films deposited at $185{ }^{\circ} \mathrm{C}$ were carbon-free and had low oxygen concentrations ( $<3$ at.\%) although $5 \mathrm{~N}$-grade $\mathrm{NH}_{3}, \mathrm{~N}_{2}$ and $\mathrm{H}_{2}$ gases were used without any further purification. Furthermore, these films were extremely smooth and showed good optical and electrical characteristics. Optical properties of these AlN thin films were investigated in detail by Alevli et al. (13). We also demonstrated conformality of the $\mathrm{AlMe}_{3}-\mathrm{NH}_{3}$ plasma PEALD process by fabricating high surface area AlN hollow nanofibers, which might potentially be used in hightemperature ambient chemical sensing applications (14).

When compared to AIN, significantly less number of publications focused on the ALD of $\mathrm{GaN}$ thin films. Growth of $\mathrm{GaN}$ by atomic layer epitaxy (ALE) using triethylgallium $\left(\mathrm{GaEt}_{3}\right)$ (15), trimethylgallium $\left(\mathrm{GaMe}_{3}\right)(16)$, and gallium trichloride $\left(\mathrm{GaCl}_{3}\right)$ (17), has been reported for temperatures $>450{ }^{\circ} \mathrm{C}$. Lower growth temperatures $\left(350-400{ }^{\circ} \mathrm{C}\right)$ were achieved when $\mathrm{GaCl}$ was used as the gallium precursor (18). Sumakeris et al. (19) reported growth of $\mathrm{GaN}$ films within the temperature range of $150-650{ }^{\circ} \mathrm{C}$ by using a novel reactor design that employs hot filaments to decompose the ammonia. Kim et al. (20) deposited $\mathrm{GaN}$ thin films by thermal ALD using $\mathrm{GaCl}_{3}$ and $\mathrm{NH}_{3}$ precursors.

Our initial efforts on depositing $\mathrm{GaN}$ thin films using $\mathrm{GaMe}_{3}$ or $\mathrm{GaEt}_{3}$ with $\mathrm{NH}_{3}$ plasma resulted in amorphous thin films with high oxygen concentrations ( 20 at.\%) (21, 22). Several experiments were carried out in order to determine the source of oxygen present in these films, and the most probable source was presumed as the oxygen impurities in the $5 \mathrm{~N}$-grade $\mathrm{NH}_{3}$ gas. However, this argument has failed when the same $\mathrm{GaN}$ deposition was repeated with the purified process gases. The true source of oxygen contamination was then found to be the quartz tube of the inductively coupled plasma source itself. Such plasma-related oxygen contamination was also reported for $\mathrm{GaN}$ thin films grown by remote plasma enhanced chemical vapor deposition (23).

In this report we review our previous and current efforts on the development of PEALD processes for III-nitrides, and present detailed characterization results for the deposited AlN and GaN thin films. 


\section{Experimental Details}

\section{$\underline{\text { Substrate Cleaning }}$}

Prior to depositions, Si (100) or Si (111) substrates were cleaned by sequential ultrasonic agitation in 2-propanol, acetone, methanol, and deionized (DI) water. Substrates were then dipped into dilute hydrofluoric acid solution (5 vol.\% HF) to remove the surface native oxide for $\sim 1-2 \mathrm{~min}$, then rinsed with DI water and dried with $\mathrm{N}_{2}$.

\section{Deposition of Thin Films}

Films were deposited on pre-cleaned substrates at temperatures ranging from 185 to $215^{\circ} \mathrm{C}$. Depositions were carried out in a Fiji F200-LL ALD reactor equipped with an inductively coupled RF-plasma source (Ultratech/CambridgeNanoTech Inc.). Trimethylaluminum $\left(\mathrm{AlMe}_{3}\right)$ and trimethylgallium $\left(\mathrm{GaMe}_{3}\right)$ were used for the deposition of AlN and $\mathrm{GaN}$ thin films, respectively. $\mathrm{AlMe}_{3}$ was kept at room temperature, whereas $\mathrm{GaMe}_{3}$ was cooled down to $6{ }^{\circ} \mathrm{C}$ using a home-made Peltier cooling system. $5 \mathrm{~N}$-grade $\mathrm{NH}_{3}, \mathrm{~N}_{2}$ and $\mathrm{H}_{2}$ plasma gases, and the carrier gas, Ar, were further purified using MicroTorr gas purifiers. Base pressure was $\sim 150$ mTorr. Remote plasma was activated at each cycle during the introduction of $\mathrm{N}$-containing plasma gas. System was purged for 10 $\mathrm{s}$ after each exposure.

\section{Characterization of Thin Films}

Ellipsometric spectra were recorded in the wavelength range of $300-1000 \mathrm{~nm}$ for AlN and $400-1200 \mathrm{~nm}$ for $\mathrm{GaN}$ thin films at three angles of incidence $\left(65^{\circ}, 70^{\circ}\right.$, and $\left.75^{\circ}\right)$ using a variable angle spectroscopic ellipsometer (J.A. Woollam). Thicknesses of the films were then obtained by modeling the measured data using Cauchy dispersion function. Chemical compositions of the films were determined by X-ray photoelectron spectroscopy (XPS) using Thermo Scientific K-Alpha spectrometer with a monochromatized Al Ka X-ray source. Etching of the samples was carried out with a beam of Ar ions having an acceleration voltage and spot size of $1 \mathrm{kV}$ and $400 \mu \mathrm{m}$, respectively. Data were corrected for charging by shifting peaks with respect to $\mathrm{C} 1 \mathrm{~s}$ or Ar 2p. X-ray reflectivity (XRR) and grazing-incidence X-ray diffraction (GIXRD) measurements were carried out in a PANalytical X'Pert PRO MRD diffractometer using $\mathrm{Cu} \mathrm{K} \alpha$ radiation. GIXRD patterns were obtained by performing 10 repeated scans within the 2Theta range of $20-80^{\circ}$ with a step size of $0.1^{\circ}$ and counting time of $10 \mathrm{~s}$. These scans were then added together in order to obtain a single GIXRD pattern with good intensity values.

\section{Results and Discussion}

\section{Deposition of GaN using $\mathrm{NH}_{3}{ }_{2} \mathrm{~N}_{2}$ and $\mathrm{N}_{2} / \underline{H}_{2}$ plasma}

Three samples were deposited at $185-215{ }^{\circ} \mathrm{C}$ using different $\mathrm{N}$-containing plasma gases, namely $\mathrm{NH}_{3}, \mathrm{~N}_{2}$, and $\mathrm{N}_{2} / \mathrm{H}_{2}$. During these experiments load lock of the PEALD system was temporarily disabled. Therefore, samples were loaded to the reactor through 
the gate while the reactor was at atmospheric pressure. The gate was then closed using a custom-made aluminum lid and the reactor was evacuated. Reactor was baked out at $250{ }^{\circ} \mathrm{C}$ for $\sim 18 \mathrm{~h}$ before each deposition.

For the film deposited with $\mathrm{NH}_{3}$ plasma, one PEALD cycle consisted of $0.015 \mathrm{~s}$ $\mathrm{GaMe}_{3}\left(\mathrm{~T}_{\text {precursor }}=6{ }^{\circ} \mathrm{C}\right) / 10 \mathrm{~s}$ Ar purge $/ 50 \mathrm{sccm}, 90 \mathrm{~s}, 300 \mathrm{~W} \mathrm{NH}$ plasma $/ 10 \mathrm{~s}$ Ar purge. For this sample, 21.5 at.\% oxygen was detected in the bulk film using ex situ X-ray photoelectron spectroscopy (XPS). In other words, the high oxygen concentration in GaN film could not be lowered by the use of purified process gases. It has been then realized that the actual source of this oxygen contamination was the etching of quartz tube in which plasma forms. For the following depositions, shorter plasma durations were used in order to avoid heating of the quartz tube and therefore minimize the sputtering of quartz. Table I summarizes the deposition conditions for $\mathrm{GaN}$ thin film samples. Elemental compositions of the deposited films are given in Table II.

TABLE I. Deposition details for GaN thin film samples.

\begin{tabular}{cccccc}
\hline Plasma Gas & $\begin{array}{c}\text { Flow Rate } \\
(\mathbf{s c c m})\end{array}$ & $\begin{array}{c}\text { Flow Duration } \\
(\mathbf{s})\end{array}$ & $\begin{array}{c}\text { Deposition } \\
\text { Temperature } \\
\left({ }^{\circ} \mathbf{C}\right)\end{array}$ & $\begin{array}{c}\text { Number of } \\
\text { Cycles }\end{array}$ & $\begin{array}{c}\text { Film } \\
\text { Thickness } \\
(\mathbf{n m})\end{array}$ \\
\hline $\mathrm{NH}_{3}$ & 50 & 90 & 185 & 1000 & 31.6 \\
$\mathrm{~N}_{2}$ & 50 & 20 & 215 & 1000 & 19.1 \\
$\mathrm{~N}_{2} / \mathrm{H}_{2}$ & $50 / 20$ & $20 / 5$ & 200 & 1000 & 22.0 \\
\hline
\end{tabular}

TABLE II. Elemental compositions of GaN thin film samples as determined by XPS survey scans. Data were collected after $60 \mathrm{~s}$ Ar ion etching.

\begin{tabular}{ccccc}
\hline Plasma Gas & Ga/N & O (at.\%) & C (at.\%) & Ar (at.\%) \\
\hline $\mathrm{NH}_{3}$ & 1.42 & 21.46 & 0.00 & 1.84 \\
$\mathrm{~N}_{2}$ & 1.07 & 4.48 & 9.12 & 0.00 \\
$\mathrm{~N}_{2} / \mathrm{H}_{2}$ & 1.04 & 4.70 & 4.20 & 0.00 \\
\hline
\end{tabular}

When $\mathrm{N}_{2}$ plasma was used instead of the $\mathrm{NH}_{3}$ plasma, oxygen concentration of $\mathrm{GaN}$ thin film decreased to 4.5 at.\%, whereas its carbon concentration increased to 9.1 at.\%. The sample deposited using $\mathrm{N}_{2}$ plasma was amorphous. We were able to deposit polycrystalline wurtzite $\mathrm{GaN}$ thin films with low oxygen and carbon concentrations (4.7 and 4.2 at.\%, respectively) at $200{ }^{\circ} \mathrm{C}$ by introducing $20 \mathrm{sccm} \mathrm{H}_{2}$ in addition to $50 \mathrm{sccm}$ $\mathrm{N}_{2}$ during the third quarter of the plasma duration. GIXRD pattern of the GaN film deposited using $\mathrm{N}_{2} / \mathrm{H}_{2}$ plasma is shown in Figure 1. These results show that carbon impurities have a detrimental effect on the crystallinity of $\mathrm{GaN}$ and introduction of $\mathrm{H}_{2}$ during the $\mathrm{N}_{2}$ plasma is crucial for achieving carbon-free III-nitride thin films.

Film thickness values obtained by fitting of the measured X-ray reflectivity (XRR) data were slightly lower than those measured by spectroscopic ellipsometry. Density values of $4.64,4.09$ and $4.91 \mathrm{~g} / \mathrm{cm}^{3}$, and roughness values of $0.49,1.16$ and $2.61 \mathrm{~nm}$ were found for GaN films deposited using $\mathrm{NH}_{3}, \mathrm{~N}_{2}$ and $\mathrm{N}_{2} / \mathrm{H}_{2}$ plasmas, respectively, using XRR. 


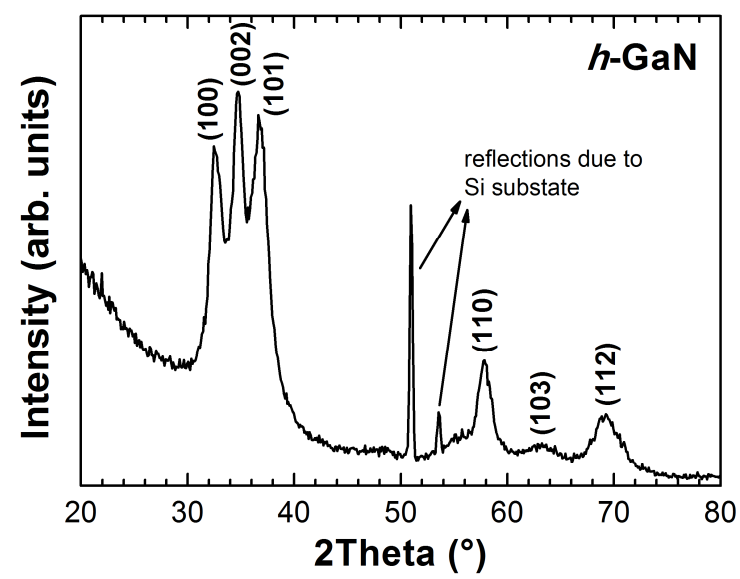

Figure 1. GIXRD pattern of a $22 \mathrm{~nm}$-thick GaN thin film deposited at $200{ }^{\circ} \mathrm{C}$ by PEALD using $\mathrm{GaMe}_{3}$ and $\mathrm{N}_{2} / \mathrm{H}_{2}$ plasma.

\section{Deposition of AlN using $\mathrm{NH}_{3}, \mathrm{~N}_{2}$ and $\mathrm{N}_{2}=\underline{\mathrm{H}}_{2}$ plasma}

Six samples were deposited at $190{ }^{\circ} \mathrm{C}$ using different N-containing plasma gases, namely $\mathrm{NH}_{3}, \mathrm{~N}_{2}$, and $\mathrm{N}_{2} / \mathrm{H}_{2}$. During these experiments load lock of the PEALD system was temporarily disabled. Therefore, samples were loaded to the reactor through the gate while the reactor was at atmospheric pressure. The gate was then closed using a custommade aluminum lid and the reactor was evacuated. Reactor was baked out at $250{ }^{\circ} \mathrm{C}$ for $\sim 12 \mathrm{~h}$ prior to each deposition. After these bake outs, the lowest vacuum value measured was $8.2 \times 10^{-6}$ Torr at $190{ }^{\circ} \mathrm{C}$. One PEALD cycle was consisted of $0.1 \mathrm{~s} \mathrm{AlMe}_{3} / 10 \mathrm{~s} \mathrm{Ar}$ purge/N-containing plasma (plasma power $=300 \mathrm{~W}$ ) $/ 10 \mathrm{~s}$ Ar purge. Deposition details for AlN thin film samples are summarized in Table III. Elemental compositions of the deposited AlN films are given in Table IV.

TABLE III. Deposition details for AlN thin film samples.

\begin{tabular}{cccccc}
\hline $\begin{array}{c}\text { Plasma Gas } \\
\text { (-Sample } \\
\text { Number) }\end{array}$ & $\begin{array}{c}\text { Flow Rate } \\
(\mathbf{s c c m})\end{array}$ & Flow Duration (s) & $\begin{array}{c}\text { Deposition } \\
\text { Temperature } \\
\left({ }^{\circ} \mathbf{C}\right)\end{array}$ & $\begin{array}{c}\text { Number of } \\
\text { Cycles }\end{array}$ & $\begin{array}{c}\text { Film } \\
\text { Thickness } \\
(\mathbf{n m})\end{array}$ \\
\hline $\mathrm{NH}_{3}$ & 50 & 20 & 190 & 500 & 33.5 \\
$\mathrm{~N}_{2}$ & 50 & 20 & 190 & 500 & 53.1 \\
$\mathrm{~N}_{2} / \mathrm{H}_{2}-1$ & $50 / 20$ & $20 / 5\left(\mathrm{H}_{2}\right.$ at $3^{\text {rd }}$ quarter $)$ & 190 & 500 & 42.9 \\
$\mathrm{~N}_{2} / \mathrm{H}_{2}-2$ & $50 / 20$ & $20 / 5\left(\mathrm{H}_{2}\right.$ at $1^{\text {st }}$ quarter $)$ & 190 & 500 & 53.8 \\
$\mathrm{~N}_{2} / \mathrm{H}_{2}-3$ & $50 / 50$ & 20 & 190 & 500 & 17.1 \\
$\mathrm{~N}_{2} / \mathrm{H}_{2}-4$ & $50 / 20$ & 20 & 190 & 500 & 20.4 \\
\hline
\end{tabular}

TABLE IV. Elemental compositions of AlN thin film samples as determined by XPS survey scans.

\begin{tabular}{cccccc}
\hline Plasma Gas & Etch Time $(\mathbf{s})$ & $\mathbf{A l} / \mathbf{N}$ & $\mathbf{O}$ (at.\%) & C (at.\%) & Ar (at.\%) \\
\hline $\mathrm{NH}_{3}$ & 150 & 1.25 & 1.51 & 3.88 & 1.90 \\
$\mathrm{~N}_{2}$ & 150 & 4.51 & 48.45 & 8.00 & 1.07 \\
$\mathrm{~N}_{2} / \mathrm{H}_{2}-1$ & 150 & 5.55 & 45.71 & 6.44 & 1.83 \\
$\mathrm{~N}_{2} / \mathrm{H}_{2}-2$ & 150 & 5.02 & 47.42 & 7.72 & 1.38 \\
$\mathrm{~N}_{2} / \mathrm{H}_{2}-3$ & 50 & 1.27 & 4.04 & 4.95 & 2.02 \\
$\mathrm{~N}_{2} / \mathrm{H}_{2}-4$ & 50 & 1.28 & 4.73 & 5.94 & 1.93 \\
\hline
\end{tabular}

In the case of $\mathrm{GaN}$ thin films, the film deposited using $\mathrm{NH}_{3}$ plasma had $\sim 20$ at. $\% \mathrm{O}$ in the bulk film. The use of $\mathrm{N}_{2}$ or $\mathrm{N}_{2} / \mathrm{H}_{2}$ plasma decreased this value to $<5$ at. $\%$. When 
same approach was followed for the deposition of AlN using $\mathrm{AlMe}_{3}$, oxygen concentration of the film increased tremendously (i.e. $>45$ at.\%). AlN samples deposited using $\mathrm{N}_{2} / \mathrm{H}_{2}$ plasma process, in which $\mathrm{N}_{2}$ and $\mathrm{H}_{2}$ are simultaneously introduced into the reactor, had 4-5 at.\% $\mathrm{O}$ and 5-6 at.\% $\mathrm{C}$ in the bulk film. For AlN, best results were obtained with the $\mathrm{AlMe}_{3}-\mathrm{NH}_{3}$ plasma process. For this sample, 3.9 at.\% $\mathrm{C}$ was found in the bulk film. In our previous work (10), we reported on the deposition of carbon-free AlN thin films with low oxygen concentrations using the same PEALD process. This suggests that $\mathrm{NH}_{3}$ plasma duration ( $20 \mathrm{vs} .40 \mathrm{~s}$ ) has a major effect on the resulting carbon concentration of AlN thin films. Samples with high oxygen concentrations were amorphous as determined by GIXRD. Samples $\mathrm{N}_{2} / \mathrm{H}_{2}-3$ and $\mathrm{N}_{2} / \mathrm{H}_{2}-4$ were also amorphous due to the $\mathrm{O}(\sim 4-5$ at.\%) and $\mathrm{C}(\sim 5-6$ at.\%) impurities. The sample deposited using $\mathrm{NH}_{3}$ plasma had lower impurity concentrations. Its GIXRD pattern revealed a weak crystallinity with broad peaks corresponding to the hexagonal wurtzite crystal structure.

XRR data were fitted using a three-layer model, i.e. $\mathrm{Si} / \mathrm{SiO}_{2} / \mathrm{Al}_{\mathrm{x}} \mathrm{O}_{\mathrm{y}} \mathrm{N}_{\mathrm{z}}$, for the films having $>45$ at.\% O. For the AlN films with low O concentrations, on the other hand, a four-layer model, i.e. $\mathrm{Si} / \mathrm{SiO}_{2} / \mathrm{AlN} / \mathrm{Al}_{2} \mathrm{O}_{3}$, has been applied. XRR results are given in Table V.

TABLE V. Thickness, density and roughness values for AIN thin film samples as determined by XRR.

\begin{tabular}{|c|c|c|c|c|}
\hline Plasma Gas & $t_{\mathrm{AIN}}$ or $\mathrm{t}_{\mathrm{AlxO \textrm {YNZ }}}$ & $\mathbf{t}_{\mathrm{Al} 203}(\mathrm{~nm})$ & $\rho\left(\mathrm{g} / \mathrm{cm}^{3}\right)$ & $\mathbf{R}_{\mathrm{rms}}(\mathbf{n m})$ \\
\hline $\mathrm{NH}_{3}$ & 31.69 & 0.35 & 2.49 & 1.01 \\
\hline $\mathrm{N}_{2}$ & 50.98 & - & 2.48 & 0.28 \\
\hline $\mathrm{N}_{2} / \mathrm{H}_{2}-1$ & 41.52 & - & 2.53 & 0.71 \\
\hline $\mathrm{N}_{2} / \mathrm{H}_{2}-2$ & 51.64 & - & 2.51 & 0.51 \\
\hline $\mathrm{N}_{2} / \mathrm{H}_{2}-3$ & 15.94 & 1.36 & 2.42 & 0.85 \\
\hline $\mathrm{N}_{2} / \mathrm{H}_{2}-4$ & 17.44 & 2.05 & 2.35 & 0.59 \\
\hline
\end{tabular}

Initial Results Obtained with the Hollow Cathode Plasma Source

We replaced the inductively coupled RF-plasma source of the Fiji F200-LL ALD reactor with a stainless steel hollow cathode plasma source (MEAglow Ltd.). Prior to depositions, system was baked out at $250{ }^{\circ} \mathrm{C}$ for $\sim 12-24 \mathrm{~h}$. Pre-cleaned, HF-dipped 4" Si (100) wafers were then introduced to the reactor via load lock. $800 \mathrm{GaN}$ cycles were deposited at $200{ }^{\circ} \mathrm{C}$ using $\mathrm{GaMe}_{3}$ and $\mathrm{N}_{2} / \mathrm{H}_{2}$ plasma, where one cycle consisted of $0.015 \mathrm{~s}$ $\mathrm{GaMe}_{3}\left(\mathrm{~T}_{\text {Precursor }}=6{ }^{\circ} \mathrm{C}\right) / 10 \mathrm{~s} \mathrm{Ar}$ purge/ $50+50 \mathrm{sccm}, 30$ or $90 \mathrm{~s}, 300 \mathrm{~W} \mathrm{~N} / \mathrm{H}_{2}$ plasma/ $10 \mathrm{~s}$ Ar purge. Table VI summarizes spectroscopic ellipsometry results obtained from these GaN thin film samples. Spectroscopic ellipsometry measurements were taken from 5 different points on the 4" Si wafer (center and edges). Using the results of these measurements, average thickness and average refractive index values were obtained. Uniformity of thickness and refractive index across the 4" wafer were also calculated and presented in Table VI. Elemental compositions of the GaN films were revealed using XPS (see Table VII). Deposited GaN films were carbon-free and had very low oxygen concentrations. Since residual water vapor on the walls of the chamber decay with each metalorganic pulse, oxygen concentration in the bulk film, which was determined as 3.02 at.\% for the first $\mathrm{GaN}$ deposition, decreased to 1.92 at.\% for the following deposition. GIXRD patterns of these GaN thin films are given in Figure 2. Both samples were polycrystalline and exhibited hexagonal wurtzite crystal structure. 
TABLE VI. Thickness and refractive index values for GaN thin films deposited by PEALD using hollow cathode plasma source.

\begin{tabular}{ccccc}
\hline $\begin{array}{c}\mathbf{N}_{2} / \mathbf{H}_{\mathbf{2}} \text { Flow } \\
\text { Duration }\end{array}$ & $\begin{array}{c}\text { Average } \\
\text { Thickness (nm) }\end{array}$ & $\begin{array}{c}\text { Uniformity of } \\
\text { Thickness (\%) }\end{array}$ & $\begin{array}{c}\text { Average } \\
\text { Refractive Index }\end{array}$ & $\begin{array}{c}\text { Uniformity of } \\
\text { Refractive } \\
\text { Index (\%) }\end{array}$ \\
\hline $90 \mathrm{~s}$ & 23.9 & \pm 1.36 & 2.24 & \pm 0.31 \\
$30 \mathrm{~s}$ & 19.5 & \pm 1.42 & 2.26 & \pm 0.55 \\
\hline
\end{tabular}

TABLE VII. Elemental compositions of GaN thin films deposited by PEALD using hollow cathode plasma source. Data were collected after $60 \mathrm{~s}$ Ar ion etching.

\begin{tabular}{ccccc}
\hline $\begin{array}{c}\mathbf{N}_{2} / \mathbf{H}_{2} \text { Flow } \\
\text { Duration }\end{array}$ & $\mathbf{G a} / \mathbf{N}$ & $\mathbf{O}($ at.\%) & C (at.\%) & Ar (at.\%) \\
\hline $90 \mathrm{~s}$ & 0.74 & 3.02 & 0.00 & 0.60 \\
$30 \mathrm{~s}$ & 0.79 & 1.92 & 0.00 & 1.12 \\
\hline
\end{tabular}

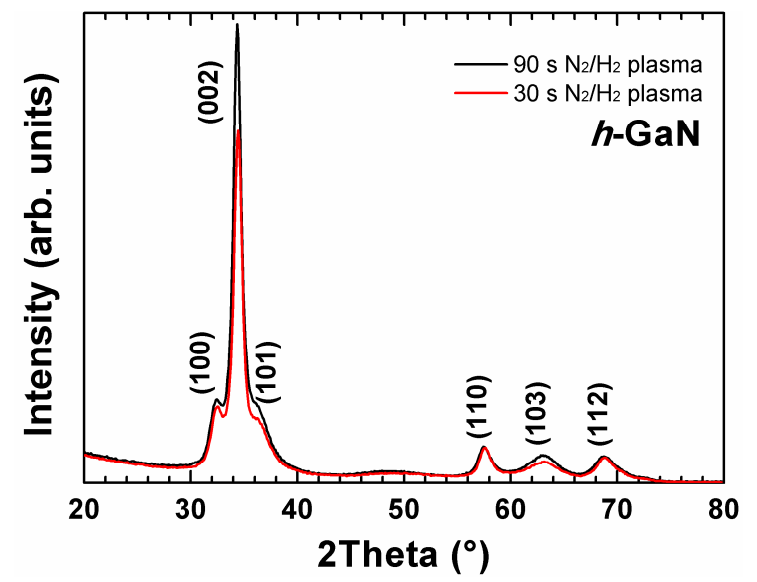

Figure 2. GIXRD patterns of GaN thin films deposited at $200{ }^{\circ} \mathrm{C}$ by PEALD using hollow cathode plasma source.

\section{Summary and Conclusions}

AlN and GaN depositions were carried out using trimethylmetal precursors in the presence of plasma-related oxygen contamination. In the case of AlN thin films, lowest oxygen concentrations were obtained using $\mathrm{NH}_{3}$ plasma $(\sim 1.5$ at.\%). Oxygen concentration in AlN films increased tremendously (i.e. $>45$ at.\%) when $\mathrm{N}_{2}$ or certain $\mathrm{N}_{2} / \mathrm{H}_{2}$ plasma processes were used. PEALD processes designed for $\mathrm{GaN}$, on the other hand, showed an adverse response to the use of $\mathrm{NH}_{3}, \mathrm{~N}_{2}$, and $\mathrm{N}_{2} / \mathrm{H}_{2}$ plasma gases in terms of oxygen incorporation. Film deposited using $\mathrm{NH}_{3}$ plasma had $\sim 20$ at. $\% \mathrm{O}$ in the bulk film. The use of $\mathrm{N}_{2}$ or $\mathrm{N}_{2} / \mathrm{H}_{2}$ plasma decreased this value to $<5$ at. $\%$. These results suggest that the severity of oxygen incorporation into AlN and $\mathrm{GaN}$ thin films are being determined by the choice of nitrogen containing plasma gas. However, this choice is highly precursor dependent and might not be anticipated for other PEALD processes. Initial results showed that polycrystalline wurtzite $\mathrm{GaN}$ thin films with low impurity contents can be deposited when the plasma-related oxygen contamination is avoided using a hollow cathode plasma source. Efforts are underway to optimize PEALD process parameters for III-nitride thin films and their ternary alloys. 


\section{Acknowledgments}

This study was supported by the State Planning Organization (DPT) of Turkey through the National Nanotechnology Research Center (UNAM) Project. Authors acknowledge M. Sowa from Ultratech/CambridgeNanoTech Inc. and S. Butcher from MEAglow Ltd. for their useful comments and suggestions. C. Ozgit-Akgun acknowledges TUBITAK-BIDEB for National PhD Fellowship. N. Biyikli acknowledges support from Marie Curie International Reintegration Grant (Grant \# PIRG05-GA-2009249196) and TUBITAK (Project \# 112M004 and 112M482).

\section{References}

1. S. C. Jain, M. Willander, J. Narayan, and R. Van Overstraeten, J. Appl. Phys., 87, 965 (2000).

2. J. Wu, J. Appl. Phys., 106, 011101 (2009).

3. Y. J. Lee and S.-W. Kang, Thin Solid Films, 446, 227 (2004).

4. Y. J. Lee, J. Cryst. Growth, 266, 568 (2004).

5. D. Riihela, M. Ritala, R. Matero, M. Leskela, J. Jokinen, and P. Haussalo, Chem. Vap. Deposition, 2, 277 (1996).

6. X. Liu, S. Ramanathan, E. Lee, and T. E. Seidel, Mater. Res. Soc. Symp. Proc., 811, D1.9 (2004).

7. D. Eom, S. Y. No, C. S. Hwang, and H. J. Kim, J. Electrochem. Soc., 153, C229 (2006).

8. M. Bosund, T. Sajavaara, M. Laitinen, T. Huhtio, M. Putkonen, V.-M. Airaksinen, and H. Lipsanen, Appl. Surf. Sci., 257, 7827 (2011).

9. K.-H. Kim, N.-W. Kwak, and S. H. Lee, Electron. Mater. Lett., 5, 83 (2009).

10. C. Ozgit, I. Donmez, M. Alevli, and N. Biyikli, Thin Solid Films, 520, 2750 (2012).

11. M. Alevli, C. Ozgit, I. Donmez, and N. Biyikli, Phys. Status Solidi A, 209, 266 (2012).

12. M. Alevli, C. Ozgit, I. Donmez, and N. Biyikli, J. Cryst. Growth, 335, 51 (2011).

13. M. Alevli, C. Ozgit, I. Donmez, and N. Biyikli, J. Vac. Sci. Technol. A, 30, 021506 (2012).

14. C. Ozgit-Akgun, F. Kayaci, I. Donmez, T. Uyar, and N. Biyikli, J. Am. Ceram. Soc., 96, 916 (2013).

15. M. A. Khan, R. A. Skogman, J. M. Van Hove, D. T. Olson, and J. N. Kuznia, Appl. Phys. Lett., 60, 1366 (1992).

16. N. H. Karam, T. Parodos, P. Colter, D. McNulty, W. Rowland, J. Schetzina, N. El-Masry, and S. M. Bedair, Appl. Phys. Lett., 67, 94 (1995).

17. H. Tsuchiya, M. Akamatsu, M. Ishida, and F. Hasegawa, Jpn. J. Appl. Phys., 35, L748 (1996).

18. A. Koukitu, Y. Kumagai, T. Taki, and H. Seki, Jpn. J. Appl. Phys., 38, 4980 (1999).

19. J. Sumakeris, Z. Sitar, K. S. Ailey-Trent, K. L. More, and R. F. Davis, Thin Solid Films, 225, 244 (1993).

20. O. H. Kim, D. Kim, and T. Anderson, J. Vac. Sci. Technol. A, 27, 923 (2009).

21. C. Ozgit, I. Donmez, M. Alevli, and N. Biyikli, J. Vac. Sci. Technol. A, 30, 01A124 (2012). 
22. C. Ozgit, I. Donmez, M. Alevli, and N. Biyikli, Acta Phys. Pol. A, 120, A-55 (2012).

23. K. S. A. Butcher, Afifuddin, P. P.-T. Chen, and T. L. Tansley, Phys. Status Solidi $C, \mathbf{0}, 156$ (2002). 